\title{
Effectiveness and safety of laparoscopic Roux-en-Y gastric bypass for the treatment of type $\mathbf{2}$ diabetes mellitus
}

\author{
PIN ZHANG, HONGWEI ZHANG，XIAODONG HAN，JIANZHONG DI，YULONG ZHOU，KUN LI and QI ZHENG \\ Department of General Surgery, The Sixth People's Hospital, Shanghai Jiao Tong University, Shanghai 200233, P.R. China
}

Received September 28, 2014; Accepted November 18, 2015

DOI: $10.3892 /$ etm.2016.2973

\begin{abstract}
Gastric bypass may be conducted to aid in glycemic control in adults with type 2 diabetes mellitus (T2DM). The aim of the present study was to investigate the clinical results of diabetes remission and metabolic syndrome in individuals with T2DM after undergoing a gastric bypass. A total of 85 patients (39 men and 46 women) with T2DM underwent laparoscopic Roux-en-Y gastric bypass (LRYGB). Data regarding patient demographics, body mass index (BMI), co-morbidities and details of diabetes mellitus, including disease duration, remission, $\beta$-cell function, blood lipid levels and nutritive status were prospectively collected and analyzed. The mean duration from the onset of T2DM was $7.79 \pm 4.84$ years (range, 1 month to 22 years). The preoperative mean BMI was $31.60 \pm 4.10$ (range, $28.53-48.10 \mathrm{~kg} / \mathrm{m}^{2}$ ), mean percentage of body fat was $36.35 \pm 9.12 \%$ (range, $18-56 \%$ ), and the mean HbAlc was $8.32 \pm 2.13 \%$ (range, $7-15.9 \%$ ). Five patients $(5.9 \%)$ developed complications without mortality. T2DM and $\beta$-cell function were significantly improved from by month 6 after surgery $(\mathrm{P}<0.05)$. Improvements in central obesity, blood pressure (BP; systolic and diastolic) control, blood lipid levels were observed, without malnutrition or severe anemia. Therefore, the present results indicate that laparoscopic RYGBP is a safe and effective procedure for improving glycemic control, obesity, body fat percentage and BP in patients with T2DM and obesity.
\end{abstract}

\section{Introduction}

Diabetes is a chronic progressive disease and the most common endocrine disorder worldwide. According to projections by the World Health Organization, the worldwide prevalence of diabetes will reach a $\sim 334$ million individuals worldwide by the 2025 (1). Another study predicted that the prevalence of

Correspondence to: Dr Qi Zheng, Department of General Surgery, The Sixth People's Hospital, Shanghai Jiao Tong University, 600 Yishan Road, Xuhui, Shanghai 200233, P.R. China

E-mail: qizheng0927@163.com

Key words: type 2 diabetes mellitus, laparoscopic Roux-en-Y gastric bypass, surgical results, follow-up diabetes in China alone will reach $\sim 100$ million individuals by 2030 (2). Furthermore, $25.8 \%$ of these patients in China received treatment for diabetes, and $39.7 \%$ of those treated had adequate glycemic control. Currently, medical interventions, including diet, exercise, and anti-diabetic medications, are the primary approaches for managing type 2 diabetes mellitus (T2DM). However, there is increasing evidence that surgery may help achieve complete remission, particularly in morbidly obese patients with diabetes (3). The positive effects of bariatric surgery on the remission of T2DM are well established (4-6). A number of conventional and experimental surgical operations have been demonstrated to markedly ameliorate T2DM, among which Roux-en-Y gastric bypass (RYGB) is the most common surgical procedure (7). A number of observational studies have detected improvements in glycemic and metabolic disorders, and diabetic complications have shown to be partially reversible due to weight loss and diabetes control. In addition, patients received beneficial reductions in cardiovascular morbidity and overall mortality.

The purpose of this retrospective study was to analyze the results of laparoscopic Roux-en-Y gastric bypass (LRYGB) treating for diabetes in Chinese people in our department, the outcome of metabolic syndrome is also discussed.

\section{Materials and methods}

Patients. The study was conducted with the approval of the ethics committee and institutional review board of the Shanghai Sixth People's Hospital (Shanghai, China). All patients provided written informed consent after being made aware of the current standards of treatment for T2DM and of risks and benefits associated with the procedure. A total of 85 patients (39 men and 46 women) with T2DM underwent LRYGB between February 2011 and May 2013. The mean age was $47.33 \pm 12.91$ years (range, $24-65$ years). The mean duration from the onset of T2DM was $7.79 \pm 4.84$ years (range, 1 month to 22 years).

Inclusion and exclusion criteria. Inclusion criteria for this study were as follows: Age, 18-65 years; BMI, >28 kg/m²; and poorly controlled T2DM as indicated by glycosylated hemoglobin (HbA1C) level of $\geq 7 \%$. Diagnosis of T2DM was based on the criteria of the American Diabetes Association (ADA) (8) and was considered valid if established by an endocrinologist or diabetes specialist. The study exclusion 
criteria were as follows: Patients $<18$ or $>65$ years old; those planning a pregnancy within 2 years after entry into the study; and patients with established diagnoses of type 1 diabetes, latent autoimmune diabetes in adults, malignancy, debilitating disease, unresolved psychiatric illness, or substance abuse.

Data collection. Data were collected prospectively and entered into a database. We collected data on patient demographics, fasting blood glucose (FBG), postprandial blood glucose (PBG), blood pressure (BP), C-peptide, insulin levels, HbAlc and blood lipid levels, including profile include cholesterol, triglyceride, high-density and low-density lipoprotein. Blood glucose was measured using the glucose oxidase method. Serum insulin and C-peptide levels were quantified using radioimmunoassays with specific insulin and C-peptide detection kits according to the manufacturer's instructions (Beijing North Institute of Biological Technology, Beijing, China). HbAlc was measured using high-performance liquid chromatography, with a former reference range of 4.0-6.0\% (Menarini Group, Florence, Italy). In addition, glycosylated serum protein (GSP) was measured using an ELISA (Hitachi 7100; Hitachi, Ltd., Tokyo, Japan). Lipid profiles were measured using standard commercial methods on a parallel, multichannel analyzer (Hitachi 7600-020; Hitachi, Ltd.). Follow-up visits were scheduled at 6,12 and 18 months after surgery. In addition, postoperative data regarding patient levels of folic acid, vitamin B12, serum iron, parathyroid hormone (PTH) and 25-hydroxy vitamin D [25(OH)D] were collected as indices of anemic and hypocalcemic status.

Patient outcome criteria. The aims for glycemic and BP control were based on the criteria established by the ADA (8). If patients were not receiving anti-diabetic medications and had normal FPG $(<100 \mathrm{mg} / \mathrm{dl})$ and HbAlc $(<6 \%)$ levels, their condition was considered to be resolved. Patients with an $\mathrm{HbAlc}$ of $\leq 7 \%$, despite no use of anti-diabetic medications, were considered to have achieved glycemic control. If the FPG decreased by $>25 \mathrm{mg} / \mathrm{dl}$ or the HbAlc reduced by $>1 \%$, the patients' condition was considered to have improved. Surgery was considered to have failed if glycemic indices showed no significant improvement, worsened or if a patient required additional anti-diabetic medication.

Surgical technique. The patient was placed in the reverse Trendelenburg position (9), with the surgeon positioned between the patient's legs. General anesthesia supplied by mechanical ventilation (Oxylog 3000 plus; Dräger, Lübeck, Germany). Five ENDOPATH XCEL ${ }^{\circledR}$ trocars (Ethicon; Johnson \& Johnson, New Brunswick, NJ, USA) were inserted under direct laparoscopic vision (Stryker 1188 HD autoclavable camera; Stryker Corporation, Kalamazoo, MI, USA). A 30-ml gastric pouch was created using 2-0 mechanical sutures (Ethicon; Johnson \& Johnson), preventing the transection of the left gastric artery. Subsequently, the angle of Treitz was identified, and a 100-cm long jejunal loop (biliopancreatic limb) was ascended anterior to the colon and anastomosed to the gastric pouch with mechanical linear suture $(30 \mathrm{~mm})$. A lateral jejuno-jejunal anastomosisadjacent to gastro-jejunal anastomosis was made at $100 \mathrm{~cm}$ from the previous nastomosis (alimentary limb), using an EC60A articulating stapler

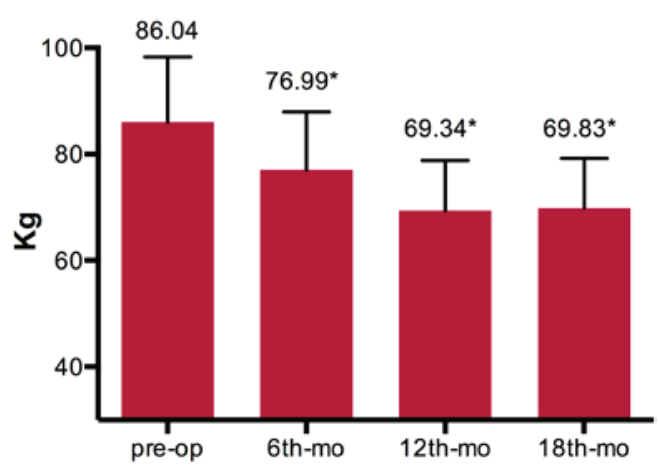

Figure 1. Mean patient body weight at pre-op and at 6, 12 and 18 mo following surgery. ${ }^{*} \mathrm{P}<0.01$ vs. preoperative levels. Pre-op, preoperative; mo, month.

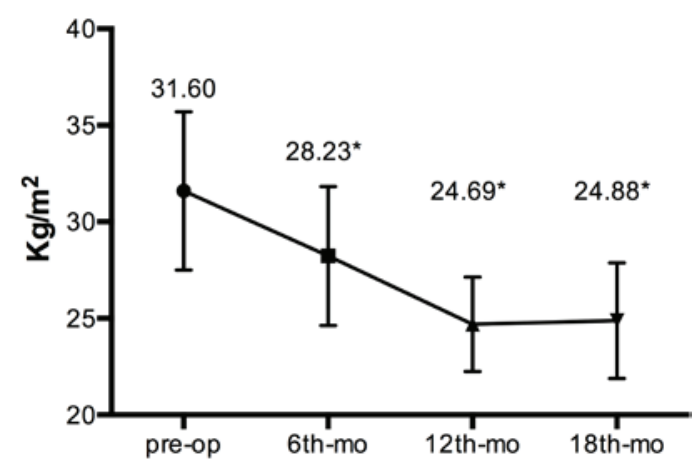

Figure 2. Mean patient body mass index at pre-op and at 6, 12 and 18 mo following surgery. ${ }^{*} \mathrm{P}<0.01$ vs. preoperative levels. Pre-op, preoperative; mo, month.

and a 6TB45 articulating linear cutter (Ethicon; Johnson \& Johnson).

Statistical analysis. Data extracted for this analysis included preoperative and postoperative body weight, BMI, blood glucose, HbAlc, BP and blood lipid. A weight loss outcome was indicated by a reduction in BMI. Blood lipid included cholesterol, triglycerides, high and low density lipoprotein (HDL and LDL). Comparisons among groups were performed by one-way analysis of variance followed by Tukey's multiple comparison test. Comparisons of means were performed using Student's $t$-test, and contingency tables of categorical variables were analyzed using Fisher's exact test. $\mathrm{P}<0.05$ was considered to indicate a statistically significant difference, and $95 \%$ confidence interval $(95 \% \mathrm{CI})$ was reported as a measure of precision. All statistical analyses were performed using SPSS statistical software, version 20.0 (IBM SPSS, Armonk, NY, USA).

\section{Results}

Preoperative patient demographics. The preoperative mean BMI was $31.60 \pm 4.10 \mathrm{~kg} / \mathrm{m}^{2}$ (range, $28.53-48.10 \mathrm{~kg} / \mathrm{m}^{2}$ ) and the mean percentage of body fat was $36.35 \pm 9.12 \%$ (range, 18-56\%). The mean HbA1c was 8.32 $\pm 2.13 \%$ (range, 7-15.9\%).

Surgical success and complications. LRYGB was successfully completed in all patients. There were no cases of patient mortality; however, 5 patients (5.9\%) developed complications. 
Table I. Metabolic syndrome improvement following laparoscopic Roux-en-Y gastric bypass.

\begin{tabular}{lcccc}
\hline Parameter & Pre-operative & 6 months & 12 months & 18 months \\
\hline Waistline (cm) & $104.26 \pm 11.51$ & $95.37 \pm 9.48^{\mathrm{a}}$ & $86.22 \pm 7.72^{\mathrm{a}}$ & $86.40 \pm 8.00^{\mathrm{a}}$ \\
Hipline (cm) & $107.42 \pm 9.64$ & $100.80 \pm 7.85^{\mathrm{a}}$ & $95.34 \pm 7.16^{\mathrm{a}}$ & $95.40 \pm 6.08^{\mathrm{a}}$ \\
Waist-hip ratio & $0.970 \pm 0.523$ & $0.946 \pm 0.057^{\mathrm{a}}$ & $0.905 \pm 0.051^{\mathrm{a}}$ & $0.91 \pm 0.055^{\mathrm{a}}$ \\
Heartrate (bpm) & $78.32 \pm 6.39$ & $77.96 \pm 10.54$ & $74.92 \pm 7.97^{\mathrm{b}}$ & $71.70 \pm 7.43^{\mathrm{b}}$ \\
Cholesterol (mmol/l) & $4.94 \pm 1.10$ & $4.68 \pm 1.08$ & $4.01 \pm 0.73^{\mathrm{a}}$ & $3.97 \pm 0.57^{\mathrm{a}}$ \\
Triglycerides (mmol/l) & $2.40 \pm 2.82$ & $1.51 \pm 0.60^{\mathrm{b}}$ & $1.14 \pm 0.47^{\mathrm{a}}$ & $1.01 \pm 0.41^{\mathrm{b}}$ \\
HDL (mmol/l) & $1.03 \pm 0.23$ & $0.98 \pm 0.18$ & $1.15 \pm 0.27^{\mathrm{b}}$ & $1.13 \pm 0.27$ \\
LDL (mmol/l) & $2.88 \pm 0.89$ & $2.90 \pm 0.89$ & $2.23 \pm 0.58^{\mathrm{a}}$ & $2.20 \pm 0.53^{\mathrm{a}}$
\end{tabular}

${ }^{a} \mathrm{P}<0.01$ and ${ }^{\mathrm{b}} \mathrm{P}<0.05$ vs. perioperative values. HDL, high density lipoprotein; LDL, low density lipoprotein.

Table II. Result of type 2 diabetes mellitus following laparoscopic Roux-en-Y gastric bypass.

\begin{tabular}{|c|c|c|c|c|}
\hline Parameter & Pre-operative & 6 months & 12 months & 18 months \\
\hline $\mathrm{FBG}(\mathrm{mmol} / \mathrm{l})$ & $8.64 \pm 2.95$ & $7.13 \pm 2.29^{a}$ & $5.78 \pm 1.29^{a}$ & $5.77 \pm 1.13^{\mathrm{a}}$ \\
\hline PBG (mmol/l) & $13.55 \pm 4.85$ & $8.32 \pm 3.18^{a}$ & $7.73 \pm 3.22^{\mathrm{a}}$ & $7.70 \pm 3.13^{\mathrm{a}}$ \\
\hline HbA1c $(\%)$ & $8.32 \pm 2.13$ & $6.97 \pm 1.22^{\mathrm{a}}$ & $6.10 \pm 0.85^{\mathrm{a}}$ & $6.23 \pm 1.16^{\mathrm{a}}$ \\
\hline GSP $(\%)$ & $20.34 \pm 6.65$ & $16.02 \pm 3.38^{\mathrm{a}}$ & $16.41 \pm 3.01^{\mathrm{a}}$ & $16.50 \pm 4.23^{\mathrm{a}}$ \\
\hline
\end{tabular}

${ }^{a} \mathrm{P}<0.01$ vs. perioperative values. FBG, fasting blood glucose; PBG, postprandial blood glucose; HbA1c, glycosylated hemoglobin; GSP, glycosylated serum protein.

One patient had intra-abdominal infection, another patient had stenosis of gastroenteric stoma, while the other 3 patients had intestinal obstruction which caused by intra-abdominal hernia. All the complications occurred in the first 30 patients, which was within the learning curve (9).

Postoperative follow-up. At the 18-month follow-up, a significant reduction in mean patient body weight was observed in comparison to the mean preoperative weight $(\mathrm{P}<0.01)$ (Fig. 1). The mean BMI decreased from $31.60 \pm 4.10 \mathrm{~kg} / \mathrm{m}^{2}$ preoperatively to $28.23 \pm 3.60,24.69 \pm 2.45$ and $24.88 \pm 2.99 \mathrm{~kg} / \mathrm{m}^{2}$ at the 6-, 12- and 18-month follow-up examinations, respectively (Fig. 2).

Metabolic syndrome indices. The changes in waistline $(\mathrm{cm})$, hipline $(\mathrm{cm})$ and waist-hip ratio in comparison to the mean preoperative weight were significant $(\mathrm{P}<0.01)$, which indicated a marked improvement in central obesity. The blood cholesterol levels were significantly decreased at the 12- and 18-month follow-up examinations $(\mathrm{P}<0.01)$ and triglycerides levels were decreased significantly at $6(\mathrm{P}=0.029), 12(\mathrm{P}=0.002)$ and 18 months $(\mathrm{P}=0.032)$ post-operation. HDL levels did not exhibit an evident change following surgery, while the LDL levels were significantly decreased at $12(\mathrm{P}=0.000)$ and 18 months $(\mathrm{P}=0.002)$ following surgery (Table I). The mean BPs (systolic/diastolic pressure, $\mathrm{mmHg}$ ) decreased from $133.61 \pm 16.12 / 84.61 \pm 10.66 \mathrm{mmHg}$ preoperatively to $[127.22 \pm 15.91 \mathrm{mmHg}(\mathrm{P}=0.043) / 79.67 \pm 8.46 \mathrm{mmHg}(\mathrm{P}=0.010)]$ at 6-months $[124.87 \pm 16.12 \mathrm{mmHg}(\mathrm{P}=0.008) / 77.58 \pm 8.68 \mathrm{mmHg}$

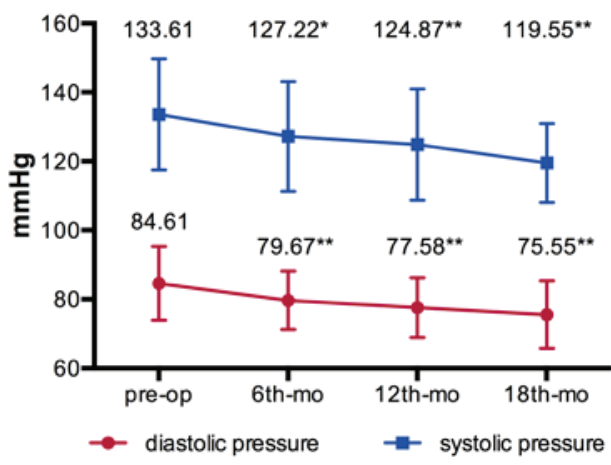

Figure 3. Mean patient systolic and diastolic blood pressure levels at pre-op and at 6,12 and 18 mo following surgery. ${ }^{*} \mathrm{P}<0.05$ and ${ }^{* *} \mathrm{P}<0.01$ vs. preoperative levels. Pre-op, preoperative; mo, month.

$(\mathrm{P}=0.001)]$ at 12 months and $[119.55 \pm 11.43 \mathrm{mmHg}$ $(\mathrm{P}=0.001) / 75.55 \pm 9.83 \mathrm{mmHg}(\mathrm{P}=0.004)]$ at 18 months post-operation (Fig. 3).

T2DM indices. Furthermore, the changes in fasting blood glucose, postprandial blood glucose, HbA1c and GSP in comparison to the mean preoperative levels were significant $(\mathrm{P}<0.01)$ (Table II). The fasting insulin levels (Ins 0') and 120 min postprandial insulin levels (Ins 120') were significantly decreased at 6, 12 and 18 months after surgery $(\mathrm{P}<0.01)$, while the $30 \mathrm{~min}$ postprandial insulin levels (Ins 30') were not significantly reduced (Fig. 4). The fasting C-peptide levels were decreased progressively without significant difference. 
Table III. Assessment of nutritive status indices following laparoscopic Roux-en-Y gastric bypass.

\begin{tabular}{lcccc}
\hline Parameter & Pre-operative & 6 months & 12 months & 18 months \\
\hline Folic acid $(\mathrm{ng} / \mathrm{l})$ & $8.57 \pm 3.07$ & $15.06 \pm 16.00^{\mathrm{a}}$ & $15.11 \pm 5.19^{\mathrm{a}}$ & $14.94 \pm 5.40^{\mathrm{a}}$ \\
Vitamin B12 $(\mathrm{ng} / \mathrm{l})$ & $580.30 \pm 293.91$ & $763.72 \pm 373.64^{\mathrm{a}}$ & $490.03 \pm 380.27$ & $443.90 \pm 342.16$ \\
Serum iron $(\mu \mathrm{mol} / \mathrm{l})$ & $16.95 \pm 5.60$ & $14.27 \pm 4.70^{\mathrm{a}}$ & $15.29 \pm 5.88$ & $16.49 \pm 5.41$ \\
PTH $(\mathrm{pg} / \mathrm{ml})$ & $37.97 \pm 14.63$ & $52.06 \pm 18.33^{\mathrm{a}}$ & $41.30 \pm 15.71^{\mathrm{a}}$ & $46.37 \pm 15.14^{\mathrm{a}}$ \\
$25(\mathrm{OH}) \mathrm{D}(\mathrm{ng} / \mathrm{ml})$ & $15.48 \pm 6.40$ & $13.62 \pm 6.48$ & $16.14 \pm 6.95$ & $17.02 \pm 8.13$ \\
\hline
\end{tabular}

${ }^{\mathrm{a}} \mathrm{P}<0.05$ vs. perioperative values. $\mathrm{PTH}$, parathyroid hormone; $25(\mathrm{OH}) \mathrm{D}, 25$-hydroxyvitamin $\mathrm{D}$.

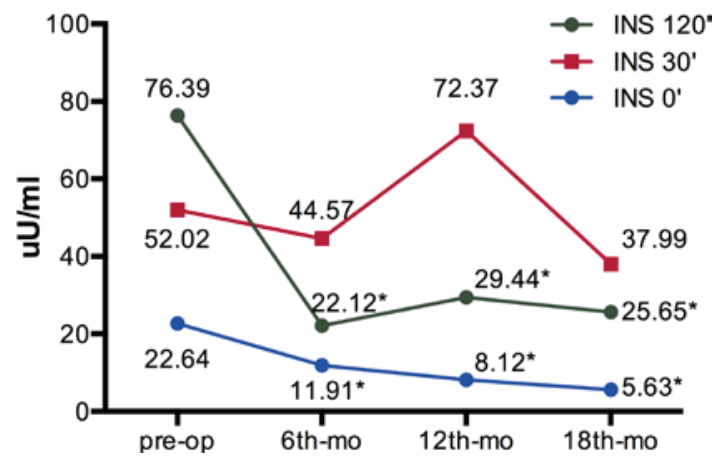

Figure 4. Mean patient insulin levels at pre-op and at 6, 12 and 18 mo following surgery. ${ }^{*} \mathrm{P}<0.01$ vs. preoperative levels. Pre-op, preoperative; mo, month; Ins 0', fasting insulin; Ins 30', 30 min postprandial insulin; Ins 120', 120 min postprandial insulin.

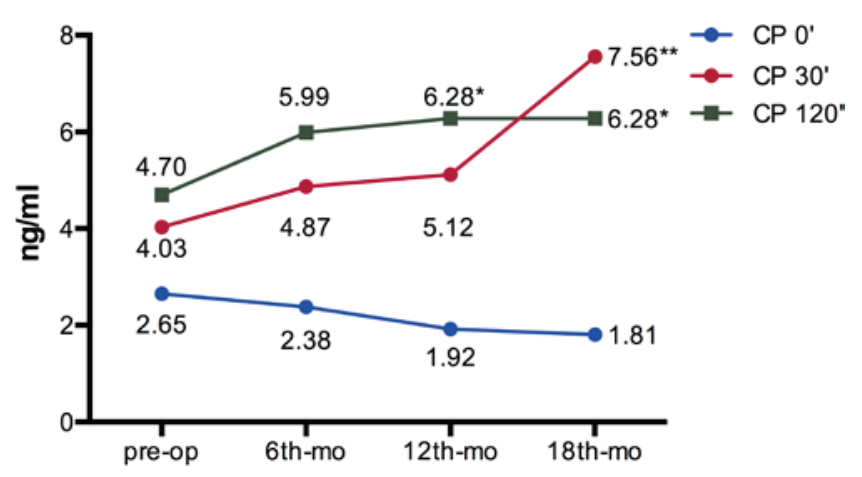

Figure 5. Mean patient C-peptide levels at pre-op and at 6, 12 and $18 \mathrm{mo}$ following surgery. ${ }^{*} \mathrm{P}<0.05$ and ${ }^{* *} \mathrm{P}<0.01$ vs. preoperative levels. Pre-op, preoperative; mo, month; CP 0', fasting C-peptide;30 CP 30', 30 min postprandial C-peptide; CP 120', 120 min postprandial C-peptide.

The 30 (CP 30') and 120 min postprandial (CP 120') C-peptide levels were increased at 6 months $\left(\mathrm{P}=0.380\right.$ for $\mathrm{CP} 30^{\prime}$ and $\mathrm{P}=0.755$ for $\left.\mathrm{CP} 120^{\prime}\right), 12$ months $\left(\mathrm{P}=0.202\right.$ for $\mathrm{CP} 30^{\prime}$ and $\mathrm{P}=0.036$ for $\left.\mathrm{CP} 120^{\prime}\right)$ and 18 months $\left(\mathrm{P}=0.001\right.$ for $\mathrm{CP} 30^{\prime}$ and $\mathrm{P}=0.024$ for $\mathrm{CP} 120^{\prime}$ ) after surgery (Fig. 5).

Nutritive status indices. Serum folic acid, vitamin B12 and serum iron levels were detected as indicators of anemia. Furthermore, the levels of PTH and 25(OH)D indicated hypocalcemic status. All patients received follow-up examinations regularly in order to assess their nutritive status, and no malnutrition or severe anemia were observed as a result of the treatments (Table III).

\section{Discussion}

Diabetes encompasses a group of chronic progressive metabolic diseases that are characterized by hyperglycemia resulting from defects in insulin secretion or activity (10). Diabetes is grouped into four clinical classes, and T2DM is the most common form of diabetes worldwide.

In the medical management of T2DM, the aim of treatment is to achieve glycemic control in order to reduce complications; which differs from the potential novel end point of euglycemia that metabolic surgery offers (11).

A previous meta-analysis that summarized the diabetic outcomes of 3,188 patients reported a resolution rate of $80.3 \%$ using LRYGB, 95.1\% after biliopancreatic diversion (BPD), and $56.7 \%$ after laparoscopic adjustable gastric banding in morbidly obese individuals (4). Metabolic surgery has been approved as an effective and potentially useful treatment for patients with T2DM and obesity $(4,12)$. Although the precise mechanisms underlying the amelioration of diabetes following surgery are poorly understood, innovative procedures based on the current understanding of mechanisms, such as duodenojejunal bypass and ileal interposition have been investigated (13-16). Furthermore, bariatric surgery has been shown to result in a significant reduction in excess weight, an effective control of comorbidities and a significant reduction in long-term mortality (17-21).

Laparoscopic RYGBP was performed in the present study as the procedure has previously been shown to be a safe and effective, with low mortality rate (0.16-0.40\%) (3) and a known morbidity rate $(7.4 \%)(22)$. Although the exact mechanism remained unclear, prior studies have indicated that weight loss, malabsorptive surgery and change in gut hormone contributed the diabetes control $(23,24)$. We recognize that the extent of excluded intestine is a point still under discussion. A previous study published by our group in 2010 showed the results in glycemic control of patients with T2DM that underwent total or subtotal gastrectomy and Roux-en-Y reconstruction with a 30-50-cm biliopancreatic limb and 70-cm alimentary limb, performed for an indication other than obesity (predominantly cancer), with a remission rate of $65 \%$ at two years of follow-up (25).

PTH may be an early detection index for a disorder of calcium-phosphate metabolism in patients with obesity and T2DM following Roux-en-Y gastric bypass (26). Sufficient supplement for relevant trace elements and regular follow-up are crucial postoperatively (27). 
Previous studies on bariatric-metabolic surgery have produced novel perspectives for the treatment of T2DM $(5,6,12)$. However, this therapeutic approach requires adjustment to further increase its effectiveness. In addition, the establishment of well-defined recommendations and guidelines for the clinical use and the definition of specific criteria for consideration of T2DM remission and control are required. Therefore, further multicenter studies are required to investigate the benefits of the surgery in different populations, by analyzing the procedures used and investigating the mechanisms involved, in order to propose a model for the development of a safe and effective surgical procedure for T2DM remission in patients with a BMI of $<28 \mathrm{~kg} / \mathrm{m}^{2}$.

In conclusion, the results of the present study suggest that LRYGB may be introduced relatively safely on a larger scale in small hospitals; with acceptable complication and mortality rates, good short-term weight loss and a valuable ameliorative effect on T2DM. However, the effects of the learning curve could not be entirely avoided. In order to ensure the surgery outcome, an appropriate surgical team and standardized surgery is necessary, which required adequate experience in order to overcome the learning curve associated with performing surgery.

\section{Acknowledgements}

This study was supported by grants from the Chinese Society of Endocrinology, Key Program of the Shanghai Municipality for Basic Research (no. 11JC1409600), the 973 program (no. 2011-CB504001) and the National Major Scientific and Technological Special Project for "Significant New Drugs Development" (no. 2011-ZX09307-001-02).

\section{References}

1. Wild S, Roglic G, Green A, Sicree R and King H: Global prevalence of diabetes: Estimates for the year 2000 and projections for 2030. Diabetes Care 27: 1047-1053, 2004.

2. Yang W, Lu J, Weng J, Jia W, Ji L, Xiao J, Shan Z, Liu J, Tian H, $\mathrm{Ji}$ Q, et al: Prevalence of diabetes among men and women in China. N Engl J Med 362: 1090-1101, 2010.

3. Buchwald H, Avidor Y, Braunwald E, Jensen MD, Pories W, Fahrbach K and Schoelles K: Bariatric surgery: A systematic review and meta-analysis. JAMA 292: 1724-1737, 2004.

4. Buchwald H, Estok R, Fahrbach K, Banel D, Jensen MD, Pories WJ, Bantle JP and Sledge I: Weight and type 2 diabetes after bariatric surgery: Systematic review and meta-analysis. Am J Med 122: 248-256, 2009.

5. Schauer PR, Kashyap SR, Wolski K, Brethauer SA, Kirwan JP, Pothier CE, Thomas S, Abood B, Nissen SE and Bhatt DL: Bariatric surgery versus intensive medical therapy in obese patients with diabetes. N Engl J Med 366: 1567-1576, 2012.

6. Mingrone G, Panunzi S, De Gaetano A, Guidone C, Iaconelli A, Leccesi L, Nanni G, Pomp A, Castagneto M, Ghirlanda G and Rubino F: Bariatric surgery versus conventional medical therapy for type 2 diabetes. N Engl J Med 366: 1577-1585, 2012.

7. Dixon JB, Zimmet P, Alberti KG and Rubino F; International Diabetes Federation Taskforce on Epidemiology and Prevention: Bariatric surgery: An IDF statement for obese Type 2 diabetes. Diabet Med 28: 628-642, 2011.

8. American Diabetes Association: Standards of medical care in diabetes - 2006. Diabetes Care 29 (Suppl 1): S4-S42, 2006.
9. Huang CK, Lee YC, Hung CM, Chen YS and Tai CM: Laparoscopic Roux-en-Y gastric bypass for morbidly obese Chinese patients: Learning curve, advocacy and complications. Obes Surg 18: 776-781, 2008.

10. American Diabetes Association: Diagnosis and classification of diabetes mellitus. Diabetes Care 33 (Suppl 1): S62-S69, 2010.

11. Rubino F, Schauer PR, Kaplan LM and Cummings DE: Metabolic surgery to treat type 2 diabetes: Clinical outcomes and mechanism of action. Annu Rev Med 61: 393-411, 2010.

12. Schauer PR, Bhatt DL, Kirwan JP, Wolski K, Brethauer SA, Navaneethan SD, Aminian A, Pothier CE, Kim ES, Nissen SE and Kashyap SR; STAMPEDE Investigators: Bariatric surgery versus intensive medical therapy for diabetes - 3-year outcomes. N Engl J Med 370: 2002-2013, 2014.

13. Rubino F, Forgione A, Cummings DE, Vix M, Gnuli D, Mingrone G, Castagneto $\mathrm{M}$ and Marescaux J: The mechanism of diabetes control after gastrointestinal bypass surgery reveals role of the proximal small intestine in the pathophysiology of type 2 diabetes. Ann Surg 244: 741-749, 2006.

14. Cohen RV, Schiavon CA, Pinheiro JS, Correa JL and Rubino F: Duodenal-jejunal bypass for the treatment of type 2 diabetes in patients with body mass index of $22-34 \mathrm{~kg} / \mathrm{m}^{2}$ : A report of 2 cases. Surg Obes Relat Dis 3: 195-197, 2007.

15. DePaula AL, Macedo AL, Mota BR and Schraibman V: Laparoscopic ileal interposition associated to a diverted sleeve gastrectomy is an effective operation for the treatment of type 2 diabetes mellitus patients with BMI 21-29. Surg Endosc 23: 1313-1320, 2009.

16. DePaula AL, Macedo AL, Schraibman V, Mota BR and Vencio S: Hormonal evaluation following laparoscopic treatment of type 2 diabetes mellitus patients with BMI 20-34. Surg Endosc 23: 1724-1732, 2009.

17. Sjöström L, Narbro K, Sjöström CD, Karason K, Larsson B, Wedel H, Lystig T, Sullivan M, Bouchard C, Carlsson B, et al: Effects of bariatric surgery on mortality in Swedish obese subjects. N Eng J Med 357: 741-752, 2007.

18. Sjöström L, Gummesson A, Sjöström CD, Narbro K, Peltonen M, Wedel H, Bengtsson C, Bouchard C, Carlsson B, Dahlgren S, et al: Effects of bariatric surgery on cancer incidence in obese patients in Sweden (Swedish Obese Subjects Study): A prospective controlled intervention trial. Lancet Oncol 10: 653-662, 2009.

19. Adams TD, Gress RE, Smith SC, Halverson RC, Simper SC, Rosamond WD, Lamonte MJ, Stroup AM and Hunt SC: Long-term mortality after gastric bypass surgery. N Engl J Med 357: 753-761, 2007.

20. Christou NV, Sampalis JS, Liberman N, Look D, Auger S, McLean AP and MacLean LD: Surgery decreases long-term mortality, morbidity and health care use in morbidly obese patients. Ann Surg 240: 416-423, 2004.

21. Csendes A, Burdiles P, Papapietro K and Burgos AM: Review of the results of medical and surgical treatment of morbid obesity. Rev Med Chil 137: 559-566, 2009 (In Spanish).

22. Nguyen NT, Hinojosa M, Fayad C, Varela E and Wilson SE: Use and outcomes of laparoscopic versus open gastric bypass at academic medical centers. J Am Coll Surg 205: 248-55, 2007.

23. Allen RE, Hughes TD, Ng JL, Ortiz RD, Ghantous MA, Bouhali O, Froguel P and Arredouani A: Mechanisms behind the immediate effects of Roux-en-Y gastric bypass surgery on type 2 diabetes. Theor Biol Med Model 10: 45, 2013.

24. Samat A, Malin SK, Huang H, Schauer PR, Kirwan JP and Kashyap SR: Ghrelin suppression is associated with weight loss and insulin action following gastric bypass surgery at 12 months in obese adults with type 2 diabetes. Diabetes Obes Metab 15: 963-966, 2013.

25. Lanzarini E, Csendes A, Lembach H, Molina J, Gutiérrez L and Silva J: Evolution of type 2 diabetes mellitus in non morbid obese gastrectomized patients with Roux en Y reconstruction: Retrospective study. World J Surg 34: 2098-2102, 2010.

26. Karefylakis C, Näslund I, Edholm D, Sundbom M, Karlsson FA and Rask E: Vitamin D status 10 years after primary gastric bypass: Gravely high prevalence of hypovitaminosis D and raised PTH levels. Obes Surg 24: 343-348, 2014.

27. Vidal P, Ramón JM, Goday A, Parri A, Crous X, Trillo L, Pera M and Grande L: Lack of adherence to follow-up visits after bariatric surgery: Reasons and outcome. Obes Surg 24: 179-183, 2014. 